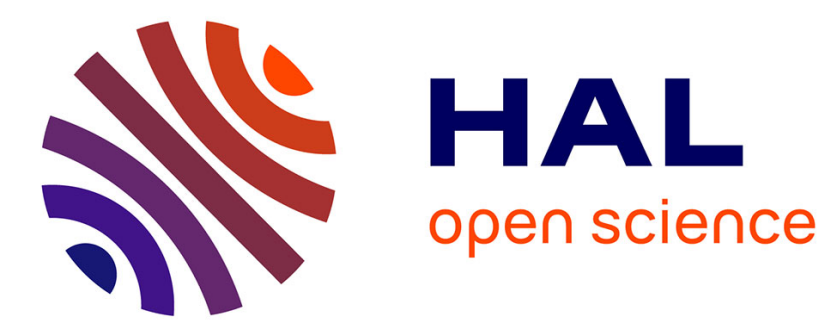

\title{
New sulfonated pyrrole and pyrrole 3-carboxylic acid copolymer membranes via track-etched templates
}

M.-C Clochard, C Baudin, N Betz, A Le Moël, C Bittencourt, L Houssiau, J.-J Pireaux, Daniel Caldemaison

\section{- To cite this version:}

M.-C Clochard, C Baudin, N Betz, A Le Moël, C Bittencourt, et al.. New sulfonated pyrrole and pyrrole 3-carboxylic acid copolymer membranes via track-etched templates. Reactive and Functional Polymers, 2006, pp.1296. 10.1016/j.reactfunctpolym.2006.03.012 . hal-01129029

\section{HAL Id: hal-01129029 \\ https://hal.science/hal-01129029}

Submitted on 11 Mar 2015

HAL is a multi-disciplinary open access archive for the deposit and dissemination of scientific research documents, whether they are published or not. The documents may come from teaching and research institutions in France or abroad, or from public or private research centers.
L'archive ouverte pluridisciplinaire HAL, est destinée au dépôt et à la diffusion de documents scientifiques de niveau recherche, publiés ou non, émanant des établissements d'enseignement et de recherche français ou étrangers, des laboratoires publics ou privés. 


\title{
New sulfonated pyrrole and pyrrole 3-carboxylic
}

\section{acid copolymer membranes via track-etched}

\section{templates}

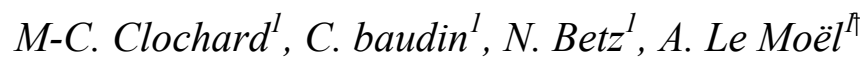 \\ C. Bittencourt ${ }^{2}$, L.Houssiau', J-J. Pireaux ${ }^{2}$
}

Daniel Caldemaison ${ }^{3}$

${ }^{1}$ CEA-Saclay, DSM/DRECAM/LSI/LPI-Bat.466, F-91191 Gif-sur-Yvette Cédex, France

${ }^{2}$ LISE, FUNDP, 61 Rue de Bruxelles, B-5000 Namur, Belgium

${ }^{3}$ LMS, Ecole Polytechnique, Route de Saclay, F-91128 Palaiseau Cédex, France

KEY WORDS : polypyrrole, track-etched membrane, diaphragmatic method, permeation, sulfonation

\footnotetext{
${ }^{\dagger}$ Corresponding author. Tel: +33-1-69-08-54-85; fax: +33-1-69-08-64-62 E-mail address :
} lemoel@drecam.cea.fr 
ABSTRACT: New copolymers of polypyrrole and poly(3-carboxylic acid pyrrole) have been synthesized via diaphragmatic method using track-etched polycarbonate matrix. The presence of carboxylic acid enables the introduction of new functionalities such as sulfonate groups. The resulting copolymer membranes with tubules microstructure have been characterized through Scanning Electron Microscopy, X-ray Photoelectron Spectroscopy, Time-of-flight Secondary Ion mass Spectrometry and FTIR. By SEM it was observed that ion-track trajectories present characteristic of crossing. FTIR, XPS and ToF-SIMS proved the attachment of the Taurin molecule to the membrane. The thermal stability study shows that the polypyrrole copolymer membranes have an exceptional stability; decomposition was not observed up to $900^{\circ} \mathrm{C}$. 


\section{Introduction}

Polypyrrole, PPy, is insoluble and infusible which restricts its processability. To overcome these restrictions, Zhitariuk and co-workers ${ }^{1}$ proposed an original way of designing PPy microstructured membranes using track-etched polymer matrix ${ }^{2}$. These membranes proved to be an important device in the field of ultra-filtration and synthetic membranes ${ }^{3}$. In recent years, PPy/Nafion composites have been the subject of numerous fundamental studies and investigations for a wide range of applications ${ }^{4,5,6}$. The combination of both the electronic conductivity of the pyrrole with the high ionic conductivity of Nafion provides some applications for PPy-rich composites in batteries ${ }^{4}$, super capacitors, and fuel cells ${ }^{5,6}$. Nafion is a well-known membrane for Proton Exchange Membrane Fuel Cell (PEMFC). Nevertheless, its thermal capacity during engine cycles is limited and its mechanical property can be affected by the presence of solvents, water content and by cation substitutions ${ }^{7}$. Even in composite form, these drawbacks remain unsolved. If the ionic conductivity as well as the ion-exchange capacity of Nafion could be conferred to the polypyrrole these drawbacks could be overcome. PPy microstructured membranes from track-etched membranes would enhance ion-exchange capacity. In combining PPy microstructured membrane technology with chemical functionalisation, the result would lead to a membrane which suits all the criteria required for an improved PEMFC.

The aim of this paper is thus to report on the synthesis of sulfonated PPy and PPy derivatives copolymers by oxidative polymerisation using track-etched templates. In fact, a substantial effect on the ionic conductivity has already been observed upon the incorporation of $\mathrm{SO}_{3}{ }^{-}$ groups in the PPy polymeric chain ${ }^{8}$. 


\section{Experimental Section}

PC track-etched membranes (pore diameter $=1 \mu \mathrm{m}$ ) were purchased from Waters. Pyrrole (Py) (Aldrich Chemicals) was distilled in vacuum and stored at $\leq 4^{\circ} \mathrm{C}$ in darkness prior to use. All the other reactants were used as received: Pyrrole 3-carboxylic acid (PyCOOH) (Acrôs), para-toluene sulfonic acid ( $p$-TSA) (Aldrich), ferric chloride hexahydrate $\left(\mathrm{FeCl}_{3}: 6 \mathrm{H}_{2} \mathrm{O}\right)$, sodium hydroxide $(\mathrm{NaOH})$, Taurin $\mathrm{C}_{2} \mathrm{H}_{7} \mathrm{O}_{3} \mathrm{NS}$ (Aldrich), ethyl-3-(3-dimethylaminopropyl)carbodiimide $\mathrm{C}_{8} \mathrm{H}_{17} \mathrm{~N}_{3} . \mathrm{HCl}$ (EDC) (Fluka-Aldrich). These solvents were analytical grade. Deionized water was used.

$\mathrm{Py}$ and $\mathrm{PyCOOH}$ copolymerisation onto PC track-etched membranes (Waters) were performed using the diaphragmatic method described by Zhitariuk et al. ${ }^{1,9}$. The twocompartment cell was separated by the PC track-etched membrane. One compartment was filled with $10 \mathrm{ml}$ solution (EtOH: $\left.\mathrm{H}_{2} \mathrm{O}\right)(50: 50)$ of Py $(0.15 \mathrm{~N}), \mathrm{PyCOOH}(0.15 \mathrm{~N})$ and p-TSA $(0.1 \mathrm{~N})$ as doping agent. The other one was filled with $\mathrm{FeCl}_{3}$ solution $(0.9 \mathrm{~N})$ as an oxidant. The initial and the modified membranes were weighed to determine the weight of the final copolymer on the matrix membranes. Dissolution of PC template membrane was then performed using $\mathrm{NaOH} 6 \mathrm{~N}$ at $80^{\circ} \mathrm{C}$ for at least 2 hours. The obtained dedoped black poly(Pyco-PyCOOH) membranes were washed twice in fresh water and 1 hour in boiled water to remove any excess $\mathrm{NaOH}$. The Poly(Py-co-PyCOOH) membranes were neutralized in acidic solution $(1 \mathrm{~N})$ for at least 2 hours before the Taurin immobilization. A coupling procedure was adopted and, after the last water washing, the clean membranes were allowed to react with $\operatorname{EDC}\left(10^{-2} \mathrm{M}\right)$ and Taurin $\left(3.2 .10^{-2} \mathrm{M}\right)$ for 24 hours in aqueous medium. The final membranes were washed again in fresh water and dried gently at room temperature.

Scanning Electron Microscopy (SEM). Scanning electron microscopy (SEM) was carried out with a Phillips apparatus equipped with $\mathrm{LaB}_{6}$ tip, and coupled with a PGT-Princeton 
Gamma Tech. X-ray detector and a PRISM Digital spectrometer. The films and the crosssections were coated with $\mathrm{Au}$ using a sputtering device before the analysis. Charge compensation with a low-energy electron flood-gun was necessary.

X-Ray Photo-electron Spectroscopy (XPS). X-ray photoelectron spectra were recorded on a HP5950A spectrometer using a monochromatic Al Ka X-ray source (1486.6 eV). The concentric hemispherical electron energy analyzer was equipped with a multichannel detector operating at a constant energy mode at an electron take-off angle of $51.5^{\circ}$. Charging effects were neutralized using a flood gun operated at $2 \mathrm{eV}$ kinetic energy. A pass energy of $150 \mathrm{eV}$ was used for both survey and core level scans. The resolution was between $0.8-1 \mathrm{eV}$. Binding energies were determined by reference to the $C_{1 S}$ component due to aromatic carbons attributed as for poly(2-vinylpyridine) (P2VP) model $^{10}$ at $285.4 \mathrm{eV}$. Linear baselines for background subtraction and Gaussian functions were used for peak fitting. Atomic percentages were determined from peak areas by using Scofield factors ${ }^{11}\left(\mathrm{C}_{1 \mathrm{~S}}=1, \mathrm{~F}_{1 \mathrm{~S}}=4.43\right.$, $\left.\mathrm{O}_{1 \mathrm{~S}}=2.93, \mathrm{~N}_{1 \mathrm{~S}}=1.8\right)$.

Time of Flight Secondary Ion Mass Spectrometry (ToF-SIMS). The mass spectra of the samples were recorded on a ToF-SIMS IV (ION-TOF GmbH) spectrometer. The secondary ions were generated by a pulsed gallium ion beam and extracted with a $2 \mathrm{keV}$ voltage. Typical analysis conditions for this work were a $25 \mathrm{keV}$ pulsed $\mathrm{Ga}^{+}$beam at a $45^{\circ}$ incidence and a 2 pA pulsed current, rastered over a $130 \mu \mathrm{m} \times 130 \mu \mathrm{m}$ area. The total ion fluency was kept below $3 \times 10^{-12}$ ions $/ \mathrm{cm}^{2}$ to ensure static conditions. The mass resolution $(\mathrm{m} / \Delta \mathrm{m})$ near mass 29 was typically 8000 . 
Infrared Spectroscopy Measurements (FTIR). FTIR spectra of polymer membrane powders were recorded on a Nicolet Magna-IR ${ }^{\mathrm{TM}} 750$ spectrometer equipped with a DTGS detector as a KBr pellet. Experiments were carried out cumulating 32 scans at a resolution of $2 \mathrm{~cm}^{-1}$.

Thermogravimetry. The thermograms TG were recorded in air atmosphere at a heating rate of $20 \mathrm{~K} / \mathrm{min}$ using a thermal analyzer (Perkin Elmer DS1410D/9928J/DAD012).

\section{Results and Discussion}

\section{Polymerisation and copolymerisation kinetics onto track-etched matrix}

Elaborations of copolymer membranes were performed using the diaphragmatic method described by Zhitariuk et al. ${ }^{1,9}$. Polycarbonate microporous membranes were used as templates. The kinetics of the Pyrrole polymerisation and the copolymerisation of the pyrrole

and pyrrole-3-carboxylic acid onto PC matrix (Figure 1) show a rapid weight gain over $5 \mathrm{hrs}$. An asymptotic variation leading to a conversion rate of $5 \mathrm{~mol} \%$ after $24 \mathrm{hrs}$ is then observed. This low conversion on the solid phase is due to the rapid diffusion of oxidant molecules and monomers through the PC matrix micropores resulting in a high conversion rate in the liquid phase. The available PC matrix area is also another parameter which limits the conversion. It is for this reason that we express the rate as a grafting rate $\mathrm{Q}(\mathrm{wt} \%)$ rather than a conversion rate. $\mathrm{Q}$ is defined as follows:

$$
Q=\frac{m_{f}-m_{P C}}{m_{P C}} \times 100
$$

where $\mathrm{m}_{\mathrm{f}}$ is the final membrane weight obtained after polymerisation, and $\mathrm{m}_{\mathrm{PC}}$ the initial PC matrix weight.

As illustrated in Figure 1, a slight difference in polymerisation kinetic appears between the homopolymer PPy and the copolymer poly(Py-co-PyCOOH $)$ at different temperatures. In 
fact, pyrrole is a very reactive monomer and is able to polymerize at low temperature $\left(0^{\circ} \mathrm{C}\right)$.In contrast, pyrrole-3-carboxylic acid monomer needs a minimum of $50^{\circ} \mathrm{C}$ to polymerize properly. Nevertheless, when the copolymerisation occurs at $50^{\circ} \mathrm{C}$, the polymerisation kinetic tends to be in the range of pyrrole homopolymerisation at $23^{\circ} \mathrm{C}$.

\section{Permeation study: a way to follow pore filling}

To study our membranes, a simple cell with a free-standing membrane was used. Pressure was supplied by vacuum. Trans-membrane pressure $(\Delta \mathrm{P})$ was $10^{4} \mathrm{~Pa}$. Ethanol permeation parameter $\mathrm{L}_{\mathrm{m}}$ was calculated as follows:

$$
L_{m}=\frac{J}{S_{m} . \Delta P}
$$

where $\quad J$ - flow rate $\left(\mathrm{m}^{3} / \mathrm{s}\right)$

$$
\mathrm{S}_{\mathrm{m}} \text { - area of membrane surface }\left(\mathrm{m}^{2}\right)
$$

Generally, three parameters describe a membrane microstructure: pore diameter $d_{P}$, pore length $1_{\mathrm{P}}$ and porosity $\delta$. They relate to macrocharacteristics of filtration by means of HagenPoiseuille equation:

$$
J=\frac{\pi \cdot d_{P}^{4} \cdot \Delta P}{128 \cdot \eta \cdot l_{P}}
$$

where $\eta$ represents the dynamic viscosity $(\mathrm{Pa} . \mathrm{s})$. This equation determines a laminar flow of liquid in one tube or pore with diameter $d_{P}$ and length $l_{P}$. If we consider $n$ pores on the membrane surface $S_{\mathrm{m}}$, equation 2 becomes:

$$
L_{m}=\frac{n . J}{S_{m} \cdot \Delta P}=\frac{n \cdot \pi \cdot d_{P}^{4}}{S_{m} \cdot 128 \cdot \eta \cdot l_{P}}
$$

therefore, $\quad d_{P}=\sqrt[4]{\frac{L_{m} \cdot l_{P} \cdot 128 \cdot \eta \cdot S_{m}}{n . \pi}}=\sqrt[4]{\frac{L_{m} \cdot l_{P} \cdot 128 . \eta}{F . \pi}}$

where F represents the pore density. 
We performed multiple polymerisations of thirty minutes each. Between each polymerisation step, we permuted the monomer and oxidant compartments in order to get homogenous surfaces. Figure 2 displays the ethanol permeation values calculated from equation 4 between each polymerisation step of PPy and poly(Py-co-PyCOOH) membranes grafted onto PC matrix. When expressing the permeability in logarithm scale, a linear relationship is observed with the polymerisation time. Poly(Py-co-PyCOOH) copolymer presents an enhanced permeability in comparison to polypyrrole. Even if the polymerisation kinetics between the copolymer and the homopolymer are comparable at the studied temperatures (Figure 1), a difference of $5 \mathrm{wt} \%$ in grafting rate between the homopolymer and the copolymer remains after 30 mins of polymerisation. It suggests that copolymer deposition during pore filling is slightly less important than homopolymer deposition. This difference may also come from a difference of structure density between the copolymer and the homopolymer ascribable to the carboxylic acid substitution at 3 position of pyrrole ring in copolymer chains.

The figure 3 displays the conversion of permeation data obtained in figure 2 into pore equivalent diameters $d_{p}$ from equation 5. It illustrates an easy way to determine pore diameters from permeation measurements and allows us to follow the polymer pore filling during polymerisation process. The exponential decay of pore diameter shows that the polymer coating thickness onto PC matrix template diminishes gradually and tends towards an asymptotic value when reaching nanopore diameters. Consequently, it becomes very improbable to obtain a PPy wire by diaphragmatic method. Different parameters coming from pore intern diameter nanoscale may govern that limit in polymer coating such as flow regime changes, polymer aromatic group electrostatic repulsions or molecular diffusion limited regime. 


\section{Final membrane microstructure}

After the PC matrix dissolution under strongly basic conditions $(\mathrm{NaOH} 6 \mathrm{~N})$, SEM micrograph shows the final membrane structure (Figure 4a). From SEM pictures, we have observed a good correlation with equivalent pore diameter calculated previously from permeation measurements. In fact, the increase in the thickness of the pore wall after successive polymerisations can be easily followed (Figures $4 \mathrm{~b}$ and $4 \mathrm{c}$ ).

Figure 5 illustrates a cross-section of poly(Py-co-PyCOOH) membrane after PC matrix removal. The ion-track trajectories are not always in one direction as is made evident by the presence of multiple crosses formed by ions tracks copolymers replica. Some irradiations were done at $+45^{\circ}$ and others at $-45^{\circ}$ leading to microtubules cross-sections of $90^{\circ}$. This irradiation strategy is used to limit tracks overlapping. It could also be interesting to use this radiation procedure to increase the final mechanical properties of this kind of membrane.

\section{Functionalization of microstructured membranes: compositional verification}

It is expected that the carboxylic acid groups of the copolymer membranes allow the anchor of Taurin molecules via common coupling reaction using water-soluble carbodiimide, EDC (scheme 1). The anchored Taurin molecules endow copolymer membranes with sulfonate functions. These sulfonate groups transfer protons and confer ion-exchange property to these new copolymer membranes.

In order to prove if Taurin immobilization was achieved, chemical analyses were performed by XPS and ToF-SIMS. Figure 6 shows the negative ToF-SIMS spectrum recorded on the Taurin powder. This spectrum is characterized by a peak at $m / z=124$ that is assigned to the Taurin molecular ion minus one hydrogen atom $\left(\mathrm{C}_{2} \mathrm{H}_{7} \mathrm{NO}_{3} \mathrm{~S}^{-}\right.$or $\left.\mathrm{M}-1\right)$. Peaks appearing below $\mathrm{m} / z 124$ give information about Taurin molecular fragmentation caused by ion impact during the ion emission process. The fragments at $\mathrm{m} / \mathrm{z}=97, \mathrm{~m} / \mathrm{z}=80, \mathrm{~m} / \mathrm{z}=64, \mathrm{~m} / \mathrm{z}=48$ and 
$m / z=32$ assigned to $\mathrm{SO}_{4} \mathrm{H}^{-}, \mathrm{SO}_{3}{ }^{-}, \mathrm{SO}_{2}^{-}, \mathrm{SO}^{-}$and $\mathrm{S}^{-}$ions respectively, can be used to monitor the Taurin immobilization as the sulphur atom is not a native element of the Poly(Py-coPyCOOH) membrane. In fact, due to the use of the $\mathrm{H}_{2} \mathrm{SO}_{4}$ solution for neutralization of the Poly(Py-co-PyCOOH) membrane, traces of sulphur related fragments were found on the ToFSIMS spectrum recorded on the membrane before the Taurin immobilization. However, on the spectrum recorded after the Taurin immobilization a low intensity peak related to the Taurin molecule appeared at $\mathrm{m} / \mathrm{z} 124$ (Figure 7) and the normalized intensity of the peaks related to the sulphur fragments increased; specifically marked was the increase of the sulfonate ion $\mathrm{SO}_{3}{ }^{-}$ion by a factor of 4.3. These suggest the presence of Taurin immobilized on the membrane. The low intensity of the Taurin molecule related peak can be associated to the fact that this molecule is strongly bonded to the surface of the membrane and during the ion bombardment it is mainly fragmented.

Figure 8 displays the comparison of the $\mathrm{C}_{1 \mathrm{~S}}$ XPS core level spectra recorded on Taurin substituted and non-substituted poly(Py-co-PyCOOH) membranes. Taurin substitution is evidenced by the peak width enlargement. Figure 9 (a) shows the $C_{1 S}$ core level spectrum recorded on the non-substituted poly(Py-co-PyCOOH) membrane, and the results of its fitting analysis. To reproduce the experimental data, four Gaussian functions and a linear background were used. Aromatic carbons (1) are attributed as for poly(2-vinylpyridine) (P2VP) model $^{10}$ at $285.4 \mathrm{eV}$. The shake up is fitted near $291 \mathrm{eV}$. The photoelectrons emitted from carbon atoms present in C-N PPy ring (2) and carboxylic acids (3) generated the Gaussians at $286.2 \mathrm{eV}$ and $289 \mathrm{eV}$ respectively. Figure 8 (b) displays the $\mathrm{C} 1 \mathrm{~s}$ core level spectrum recorded on Taurin substituted poly(Py-co-PyCOOH) membrane. To properly reproduce this data, apart from the four previously used Gaussians functions, two others were added to the fitting analysis. The new Gaussians functions were generated by photoelectrons 
emitted from carbon atoms in $\mathrm{C}-\mathrm{S}$ groups (5) at $285.8 \mathrm{eV}$ and from carbon atoms in amide groups (4) at $288.2 \mathrm{eV}$.

Comparing the results of the peak analysis, it was found that the area of the peak associated to carboxylic acid near $289 \mathrm{eV}$ decreases from $11.2 \%$ (theoretical value equates to $11.1 \%$ ) to $5.7 \%$ while the area of the C-N peak increases from $38.4 \%$ up to $41.3 \%$ and the area of the $\mathrm{C}=\mathrm{C}$ peak decreases from $42.8 \%$ to $27.3 \%$. The increase in the $\mathrm{C}-\mathrm{N}$ peak area and the decrease of $\mathrm{C}=\mathrm{C}$ peak area supports the assumption of Taurin immobilization. In fact, as shown on scheme 1, the chemical composition of the Taurin adds a $\mathrm{C}-\mathrm{N}$ bond conferring a theoretical $1.45 \%$ increase of $\mathrm{C}-\mathrm{N}$ content (2) and globally the $\mathrm{C}=\mathrm{C}$ contribution (1) decreases theoretically from $44 \%$ in carbon content for poly(PPy-co-PPyCOOH) to $36 \%$ for poly(PPy-co-CONH-Taurin). Although a relatively good correlation, the variations observed from theoretical values show that the membranes surface chemical composition is slightly different from the simple scheme model. The remaining $5.7 \%$ carboxylic acid moieties suggests: i) the presence of PPy oxidation residue ${ }^{12}$ and/or ii) a non-complete substitution which can be caused by a lack of accessibility of some carboxylic acid sites.

Figure 10 displays FTIR spectra of poly(Py-co-PyCOOH) and poly(Py-coPyCONHTaurin). The bands at 1040 and $1107 \mathrm{~cm}^{-1}$ represent, respectively, the symmetric and asymmetric streching vibration of the sulfonated group. It is important to note that the peak at $1700 \mathrm{~cm}^{-1}$ in spectrum (a) which corresponds to $\mathrm{C}=\mathrm{O}$ vibration of the carboxylic acid decreased after Taurin attachment in favour of amide I peak arising at $1640 \mathrm{~cm}^{-1}$ and amide II peak at $1569 \mathrm{~cm}^{-1}$.

\section{Microstructured membranes thermal stability}

Thermogravimetric analysis (TGA) can be used to assess the thermal stability of each polymer membrane. The TGA curves measured under flowing nitrogen are shown in figure 
11. The polypyrrole powder is obtained by oxidative polymerisation in solution under the same experimental conditions used for synthesis of PPy microstructured membranes. The TGA curve of the dedoped polypyrrole powder is similar to those obtained previously ${ }^{13}$ in $\mathrm{N}_{2}$. The TG of the polypyrrole powder shows only one major weight loss step at $475^{\circ} \mathrm{C}$ from derivative curve event. There is a small weight loss of $8 \%$ below $100^{\circ} \mathrm{C}$ corresponding to water content. When polypyrrole has been synthesized by diaphragmatic method and the resulting PPy microstructured membrane revealed by matrix dissolution, we observed unexpected thermal behaviour. In fact, under thermal treatment, PPy membranes behave completely differently from PPy in solution showing no decomposition event, even when heating up to $900^{\circ} \mathrm{C}$ (Figure 11). This exceptional thermal stability is also observed for copolymer membranes. It is not affected by Taurin modification.

The lowest energy conformation of a polypyrrole chain is an arrangement in which the pyrrole rings in the chain are co-planar. An increased proportion of planar PPy segments induces a concomitant increase in conductivity ${ }^{14}$. A helical coil conformation is also possible if the alternation of ring orientation is irregular. In our case, no organisation of PPy chains occurs during polymerisation in solution and a polymer coil is obtained randomly. Inversely, the pattern of PC matrix porous membranes forces PPy chains to organize themselves in the lowest energy conformation. Jinbo H. et al. ${ }^{15}$ recently studied the ordered structure of the surface of PPy nanotubules by growing potentiostatically PPy nanotubules using alumina membranes. They reach the conclusion that the pyrrole ring lay parallel to the alumina template wall. Considering the research above, in this kind of oriented structure the polymer chains can align more tightly, which explains the reported conductivity enhancement. It also plays a role in material mechanical properties. Because the thermal stability depends on the conductivity behaviour and the mechanical properties, it is possible to link these 
considerations as a plausible explanation for the obtained TG results on PPy and PPy derivatives membranes.

\section{Conclusions}

Copolymers of polypyrrole and poly(3-carboxylic acid pyrrole), noted poly(Py-coPyCOOH), have been successfully synthesized via diaphragmatic method using track-etched PC matrix. Permeation data allowed us to follow equivalent pore diameter decrease with polymerisation time. Each pore diameter calculated from permeation data was confirmed by SEM. We could observe that polymer deposition layer on PC matrix was thicker in the case of homopolymer as compared to copolymer of pyrrole. This difference was ascribed to grafting rate variations and structural difference between the copolymer and the homopolymer. After PC matrix dissolution, poly(Py-co-PyCOOH) membranes with tubular microstructures were obtained. The tubules presented the characteristic of crossing ion tracks.

The resulting membranes with tubular microstructure should exhibit an enhanced ionexchange capacity because of their great specific surface. In order to bring them the ionexchange capacity, sulfonated groups have been covalently binded by coupling reaction with carboxylic acid moieties present onto the copolymer backbone. Sulfonation by coupling reaction with Taurin was verified by XPS, ToF-SIMS and FTIR. It suggests that other functionalities can be introduced using this protocol on such copolymer microstructured membranes, opening a vast field of applications.

The thermal stability of the membranes was also studied. It has shown no decomposition event up to $900^{\circ} \mathrm{C}$, even after sulfonation by Taurin immobilization. Such a thermal stability on PPy derivatives has not yet been reported and it points out the great impact of the structure on the thermal behaviour. This is of great interest concerning PEMFC applications. 


\section{Acknowledgements}

The authors would like to thank Dr Caroline Aymes-Chodur (University of Pharmacy,

Châtenay-Malabry, France) for her help on thermogravimetry analysis.

\section{References}

(1) Zhitariuk, N. I.; Le Moël, A.; Memilliod, N.; Trautman, C. nucl. instr. and meth. 1995, 105, 204.

(2) Spohr, R. Ions Tracks and Microtechnology. Principles and Application.; Friedr. Vieweg\&Sohn Verlegsgschaft mbH: Braunschweig, 1990.

(3) Demoustier-champagne, S.; Ferain, E.; Jérôme, C.; Jérôme, R.; Legras, R. Eur. Polym. J. 1998, 12, 1767-1774.

(4) Blasiak, M.; Golimowski, J.; Maksymiuk, K. Pol. J. Chem. 2001, 75, 1719.

(5) Langsdorf, L. L.; Sultan, J.; Pickup, P. G. J. Phys. Chem. B 2003, 107, 8412-8415.

(6) Easton, E. B.; Langsdorf, B. L.; Hugues, J. A.; Sultan, J.; Qi, Z.; Kaufman, A.; Pickup, P. G. Journal of The Electrochemical Society 2003, 150, C735-C739.

(7) Kawano, Y.; Wang, Y.; Palmer, R. A.; Aubuchon, S. R. Polimeros: Ciencia e Tecnologia 2002, 12, 96-101.

(8) Sahin, Y.; Aydin, A.; Arslan Udum, Y.; Pekmez, K.; Yildiz, A. Journal of Applied Polymer Science 2004, 93, 526-533.

(9) Ermolaev, S. V.; Jitariouk, N.; Le Moël, A. Nuclear Instruments and Methods in Physics Research B 2001, 185, 184-191.

(10) Beamson, G.; Briggs, D. high resolution XPS of organic polymers: the Scienta ESCA300 database; John Wiley \& Sons Ltd., 1992.

(11) Scofield, J. H. J. Electron Spectrosc. Relat. Phenom. 1976, 8, 129.

(12) De Giglio, E.; Losito, I.; Dagostino, F.; Sabbatini, L.; Zambonin, P. G.; Torrisi, A.; Licciardello, A. Annali di Chimica 2004, 94, 207-218.

(13) Syed Abthagir, P.; Saraswathi, R. Materials Chemistry and Physics 2005, 92, 21-26.

(14) Avlyanov, J. K.; Kuhn, H. H.; Josefowicz, J. Y.; MacDiarmid, A. G. Synthetic Metals 1997, 84, 153-154.

(15) Jinbo, H.; Wei, C.; Ning, X.; Liang, L.; Xingwei, L.; Gi, X. Applied Surface Science 2004, 87-92. 
Scheme 1. Taurin immobilization onto poly(PPy-co-PPyCOOH) membrane

Figure 1: Polymer mass variation onto $\mathrm{PC}$ matrix versus polymerisation time: $\mathrm{PPy}$ at $23^{\circ} \mathrm{C}$ (๑), poly(Py-co-PyCOOH) at $50^{\circ} \mathrm{C}(\mathrm{O})$.

Figure 2: Ethanol permeabilities of PPy (O) and poly(Py-co-PyCOOH) (○) membranes onto PC matrix at different polymerisation time

Figure 3: Equivalent pore diameters of $\mathrm{PPy}(\mathbf{O})$ and poly $(\mathrm{Py}-\mathrm{co}-\mathrm{PyCOOH})(\mathrm{O})$ membranes onto PC matrix versus polymerisation time

Figure 4: PPy membranes after PC matrix dissolution a) one polymerisation step, b) three polymerisation steps, c) ten polymerisation steps

Figure 5: SEM micrograph of a cross-section of poly(Py-co-PyCOOH) (50:50) membrane : $\varnothing_{\text {tubes }}=1 \mu \mathrm{m}$; pore length $=18 \mu \mathrm{m} ;$ wall thickness $=240 \mathrm{~nm}$

Figure 6: Typical Taurin low-mass negative ToF-SIMS spectrum

Figure 7: Typical Taurin substituted poly(Py-co-PyCOOH) low-mass negative ToF-SIMS spectrum

Figure 8: XPS $C_{1 s}$ core level spectra of Taurin substituted $(\Delta)$ and non-substituted poly(Py-co-PyCOOH) (50:50) -spectra were normalized at 30 scans-

Figure 9: $\mathrm{XPS} \mathrm{C}_{1 \mathrm{~S}}$ core level spectrum of (a) poly(Py-co-PyCOOH) (50:50) -30 scans- and (b) Taurin substituted poly(Py-co-PyCOOH) (50:50) -50 scans- : ( $\diamond)$ raw data; (-) fit result; $(--)$ base line; $(\diamond) \mathrm{C}=\mathrm{C}$ P2VP equivalent; $(\Delta) \mathrm{C}-\mathrm{S} ;(\boldsymbol{\Delta})=\mathrm{C}-\mathrm{N} ;(\boldsymbol{\square})$ amide; $(\boldsymbol{\nabla}) \mathrm{COOH} ;(\bigcirc)$ shake up

Figure 10: FTIR spectra in transmission mode of (a) poly(Py-co-PyCOOH) (50:50) [-] and (b) Taurin substituted poly(Py-co-PyCOOH) (50:50) [-]-32 scans-

Figure 11: TGA curves of PPy powder $\left(-_{\Delta^{-}}\right)$, PPy membrane $(-)$, Taurin substituted poly(Py-co-PyCOOH) (---), poly(Py-co-PyCOOH) (-.--) 



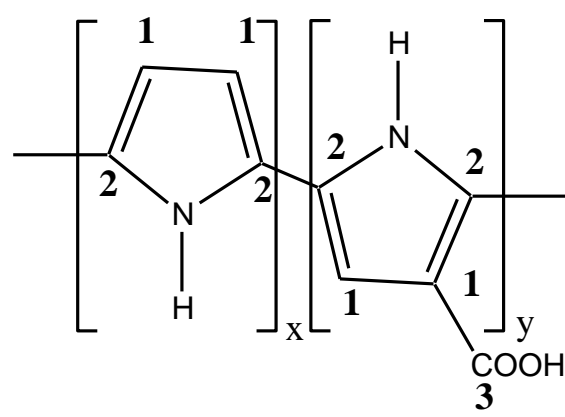

Poly(PPy-co-PPyCOOH)

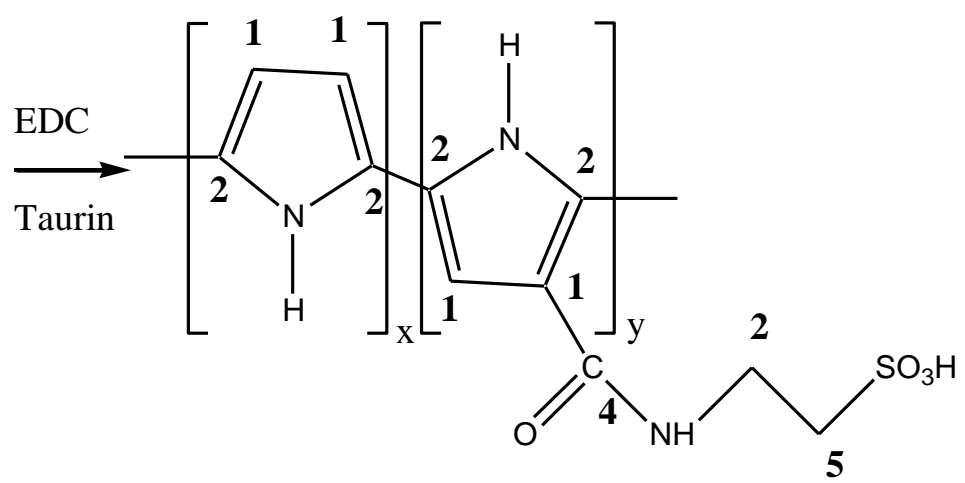

Poly(PPy-co-PPyCONHtaurin)

Scheme 1 


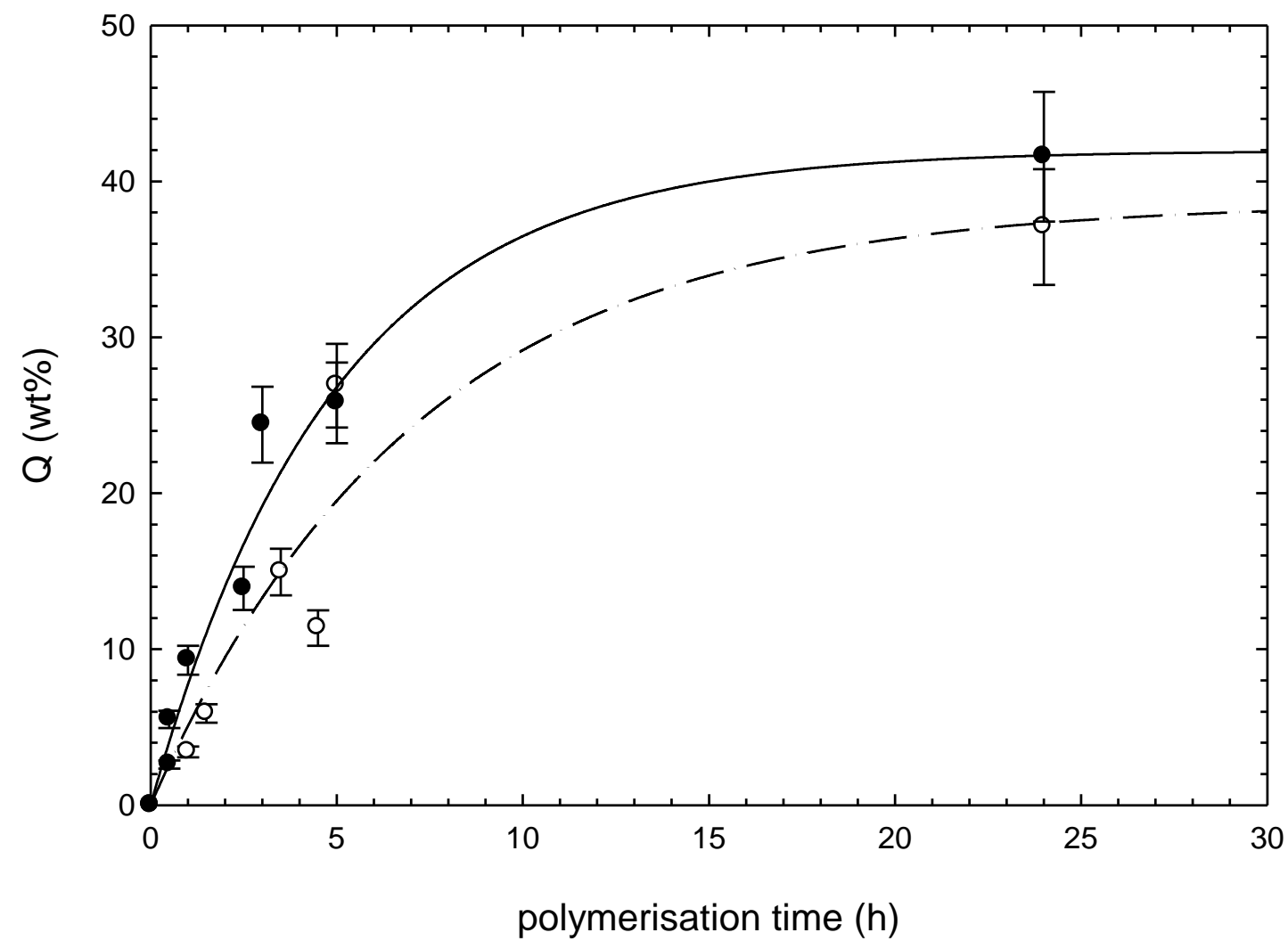

Figure 1 


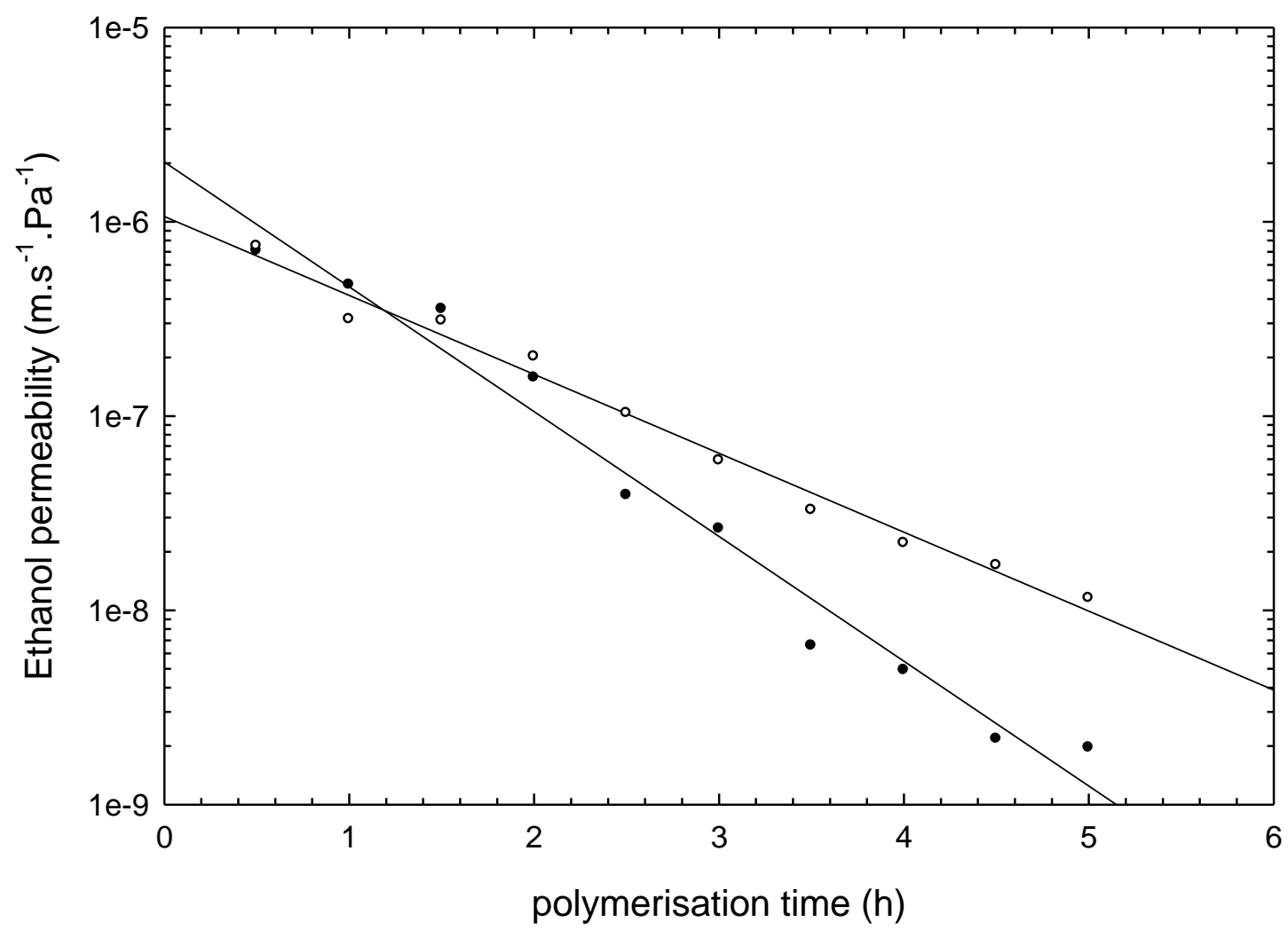

Figure 2 


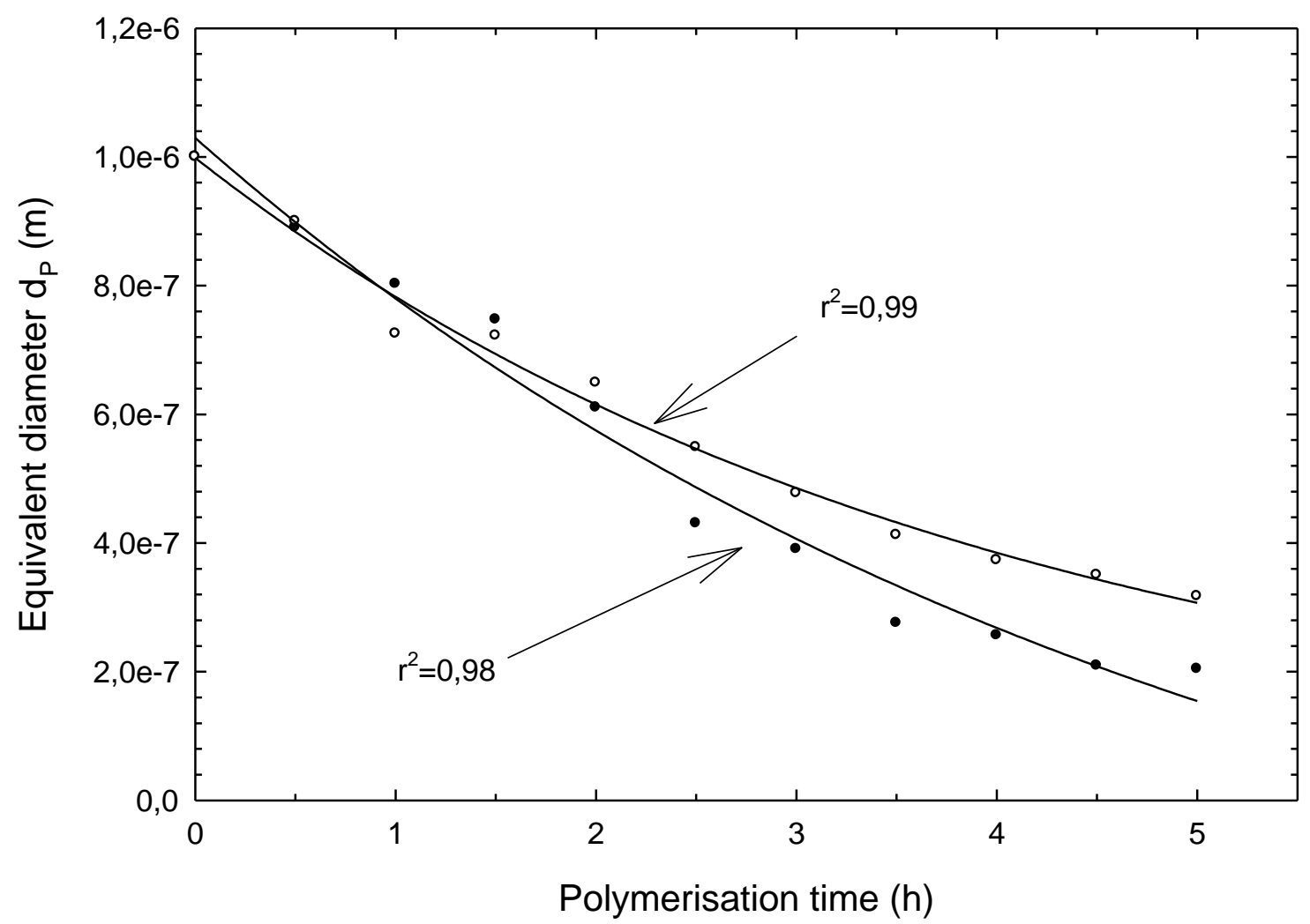

Figure 3 

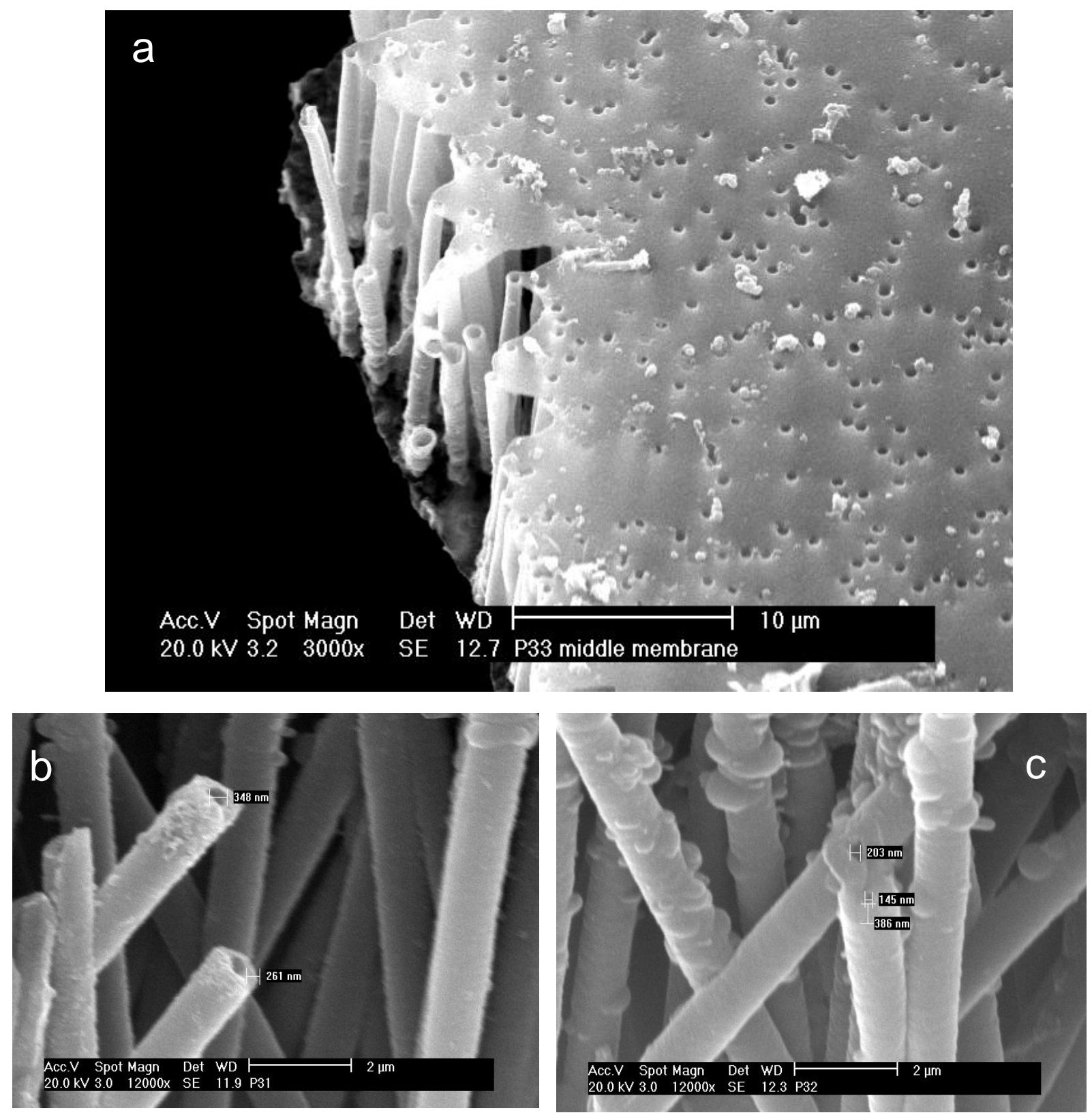

Figure 4 


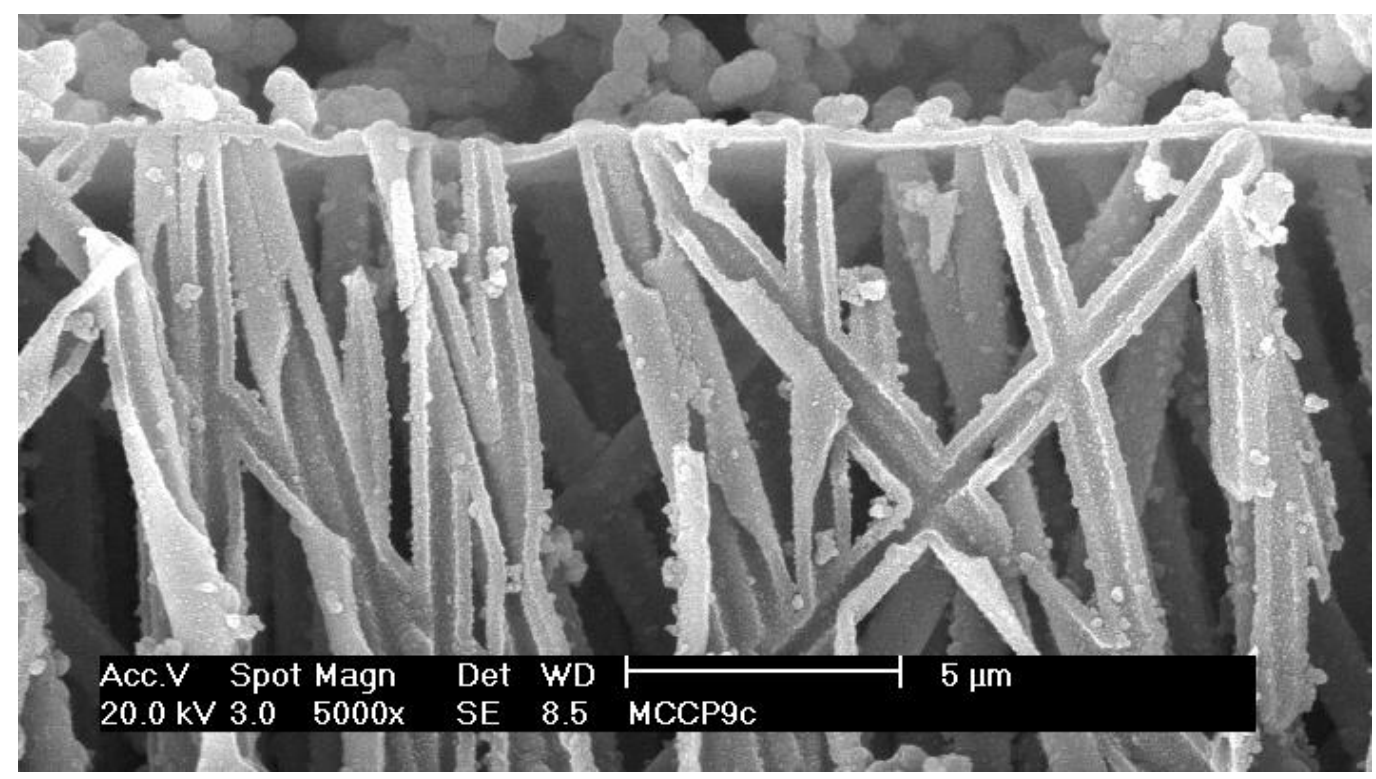

Figure 5 


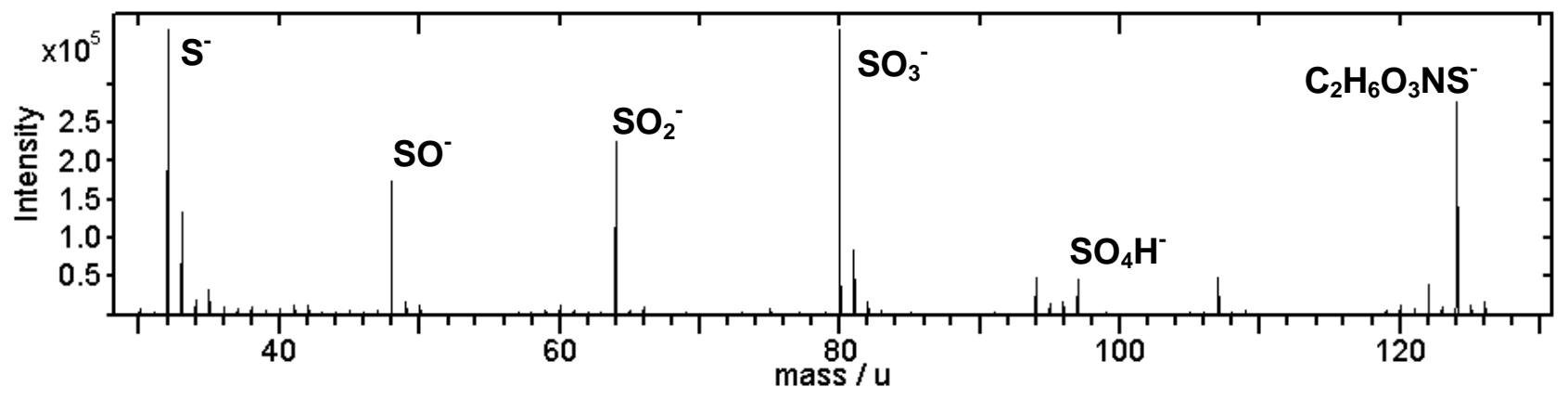

Figure 6 


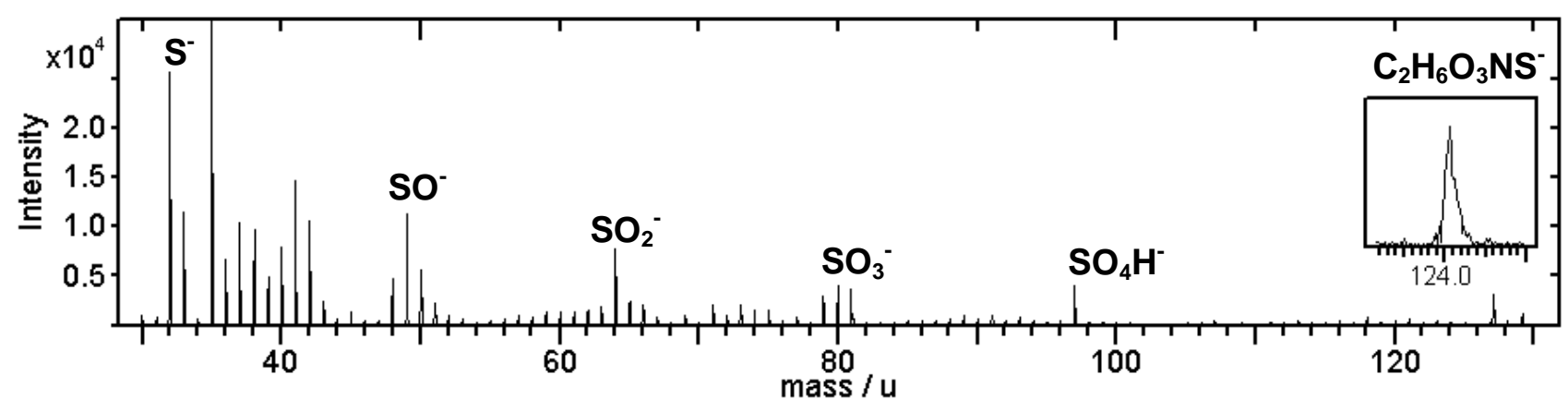

Figure 7 


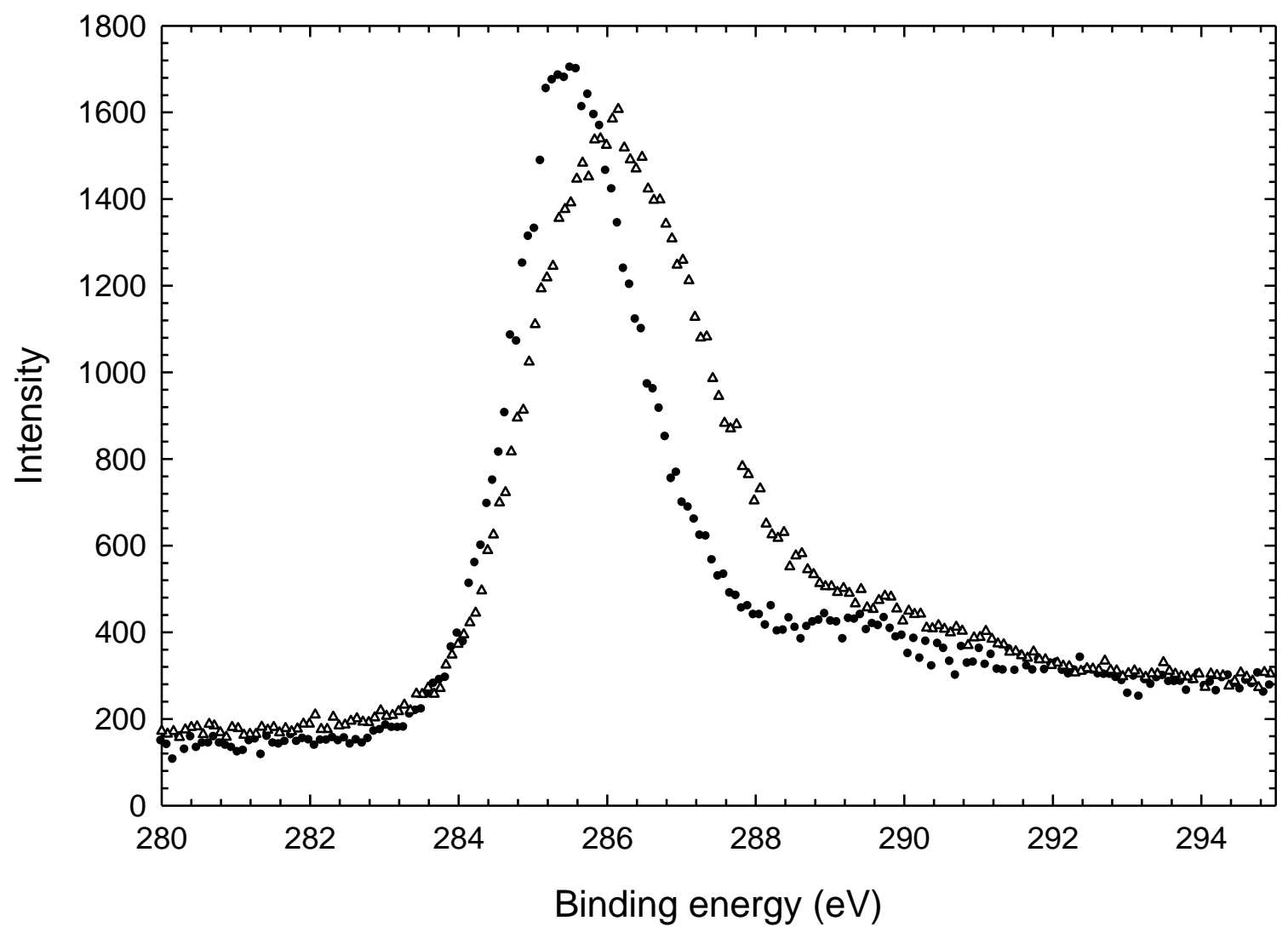

Figure 8 

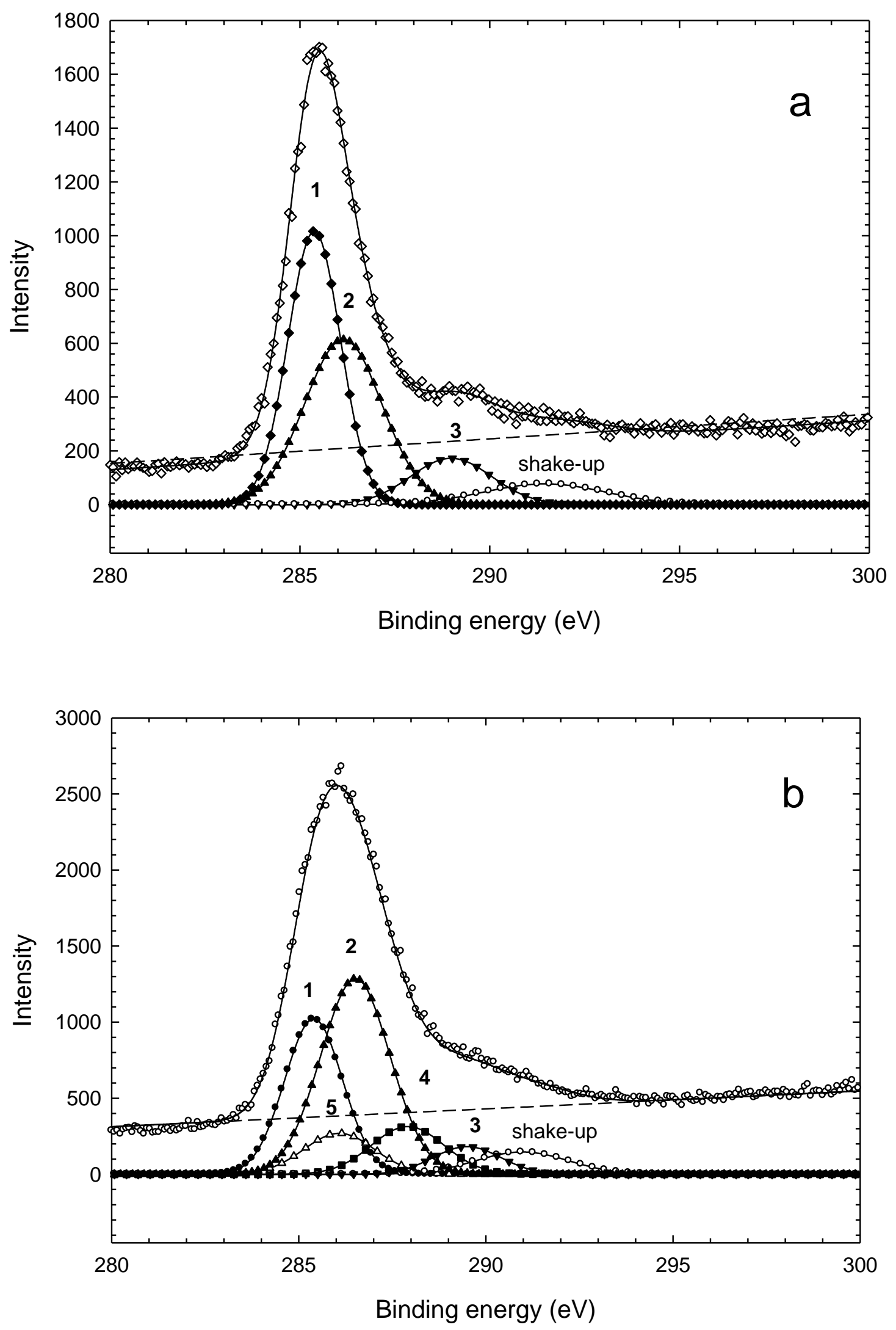

Figure 9 


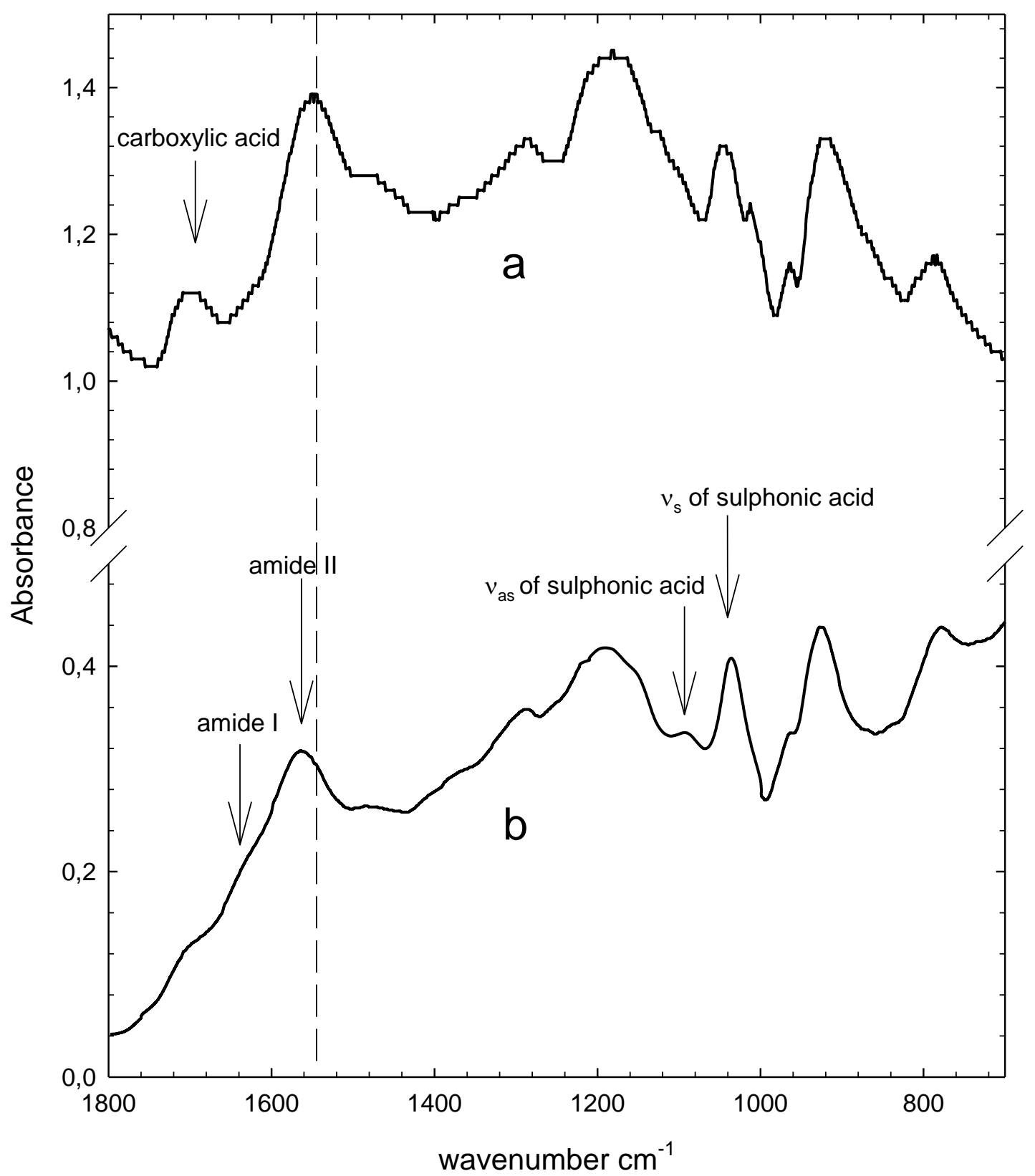

Figure 10 


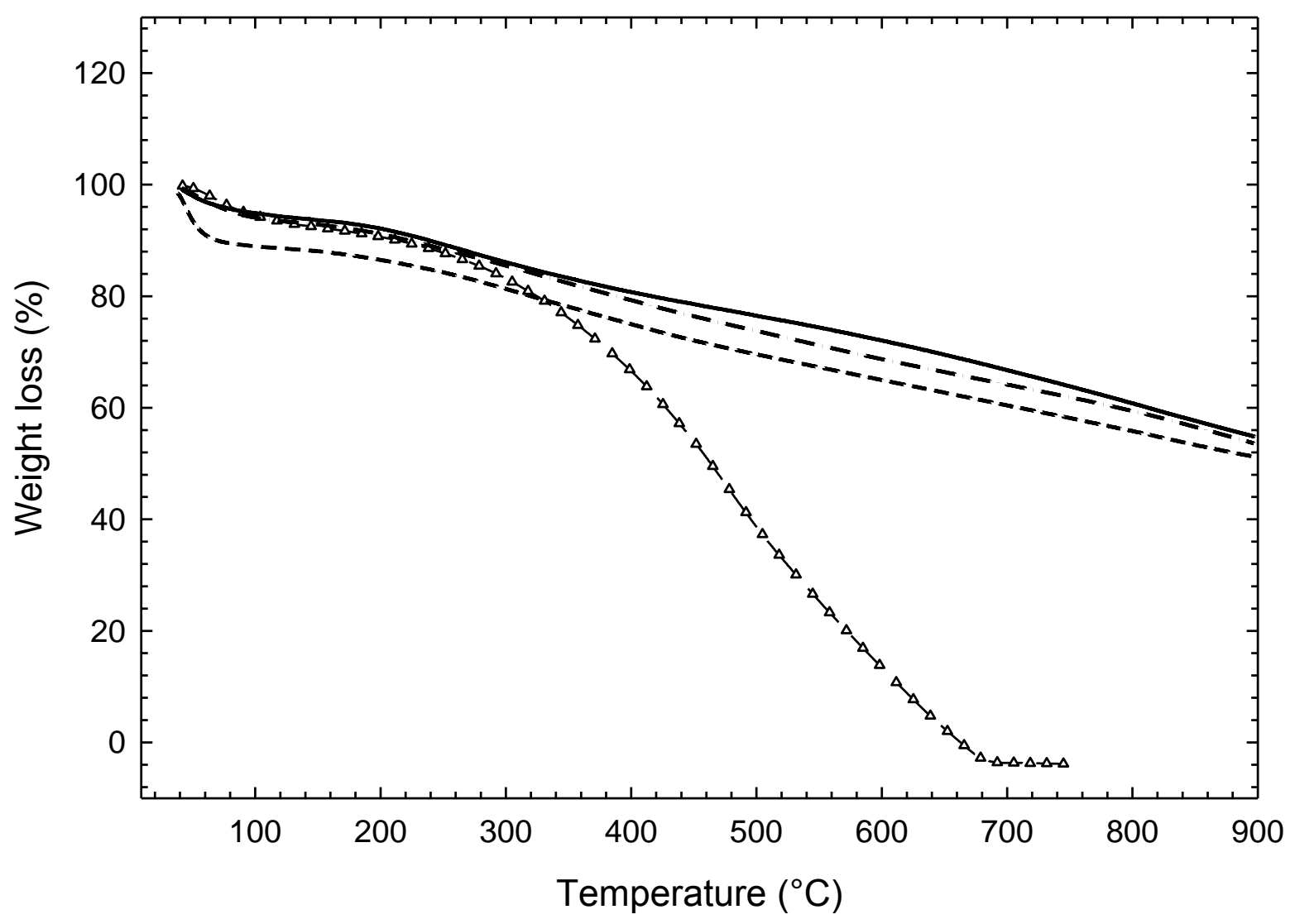

Figure 11 